\title{
Maximising health literacy and client recall of clinical information: An exploratory study of clients and speech- language pathologists
}

\author{
Friderike Schmidt von Wühlisch \\ Michelle Pascoe \\ Division of Communication Sciences and Disorders, Faculty of Health Sciences, University of Cape Town
}

Correspondence to: F Schmidt von Wühlisch (friderike.svw@gmail.com)

\begin{abstract}
Limited research has been carried out in the field of speech-language pathology with regard to ways of maximising health literacy and client recall. However, speech-language pathologists (SLPs) frequently provide vast amounts of information that clients need to understand, apply and review in order to manage their (or their child's) health. This exploratory study aimed to contribute information about ways in which SLPs can overcome low health literacy and poor client recall so that treatment effectiveness is improved. A case-study design was used with specific focus on four clients receiving treatment for dysphagia, voice disorders (including laryngectomies) and cleft lip and/or palate management in Cape Town. Strategies which may be able to maximise health literacy and client recall of clinical information were trialled and evaluated by clients and their SLPs, using semi-structured interviews. The researchers proposed a combination of high-tech strategies which assisted in all the cases. No single solution or universal tool was found that would be appropriate for all. There is a need to evaluate the long-term effectiveness of the combined strategies across a wider population, at different stages of rehabilitation and in diverse contexts. Implications and suggestions for future related research are presented.
\end{abstract}

Keywords: adherence, effectiveness, health literacy, intervention, recall

Clients in the health care sector frequently struggle to understand and remember details of clinical information and reasons underlying their treatment. As a result, they often do not adhere to clinical instructions and recommendations, which contributes to a reduction in the effectiveness and efficiency of health care interventions (Kessels, 2003). Therefore, to support clients in managing their own health, clients need to be provided with a documented record of client-specific clinical information (Osborne, 2008a \& 2008b; Santo, Laizner \& Shohet, 2005). This poses specific challenges for people who have low literacy skills as they have fewer means to either improve their health literacy (e.g. through the Internet) or review health advice because they cannot read written materials.

In the field of speech-language pathology, little research has been conducted with regard to health literacy and client recall. However, speech-language pathologists (SLPs) frequently provide vast amounts of information that clients need to understand, apply and review in order to manage their (or their child's) health. This study responds to the need to investigate conventional and unconventional strategies of maximising health literacy and client recall post consultation.

\section{Health literacy: A background}

Health literacy is defined as 'the degree to which individuals have the capacity to obtain, process, and understand basic health information and the services needed to make appropriate health decisions' (Institute of Medicine (IOM), 2004, p. 1). Clients with low health and general literacy skills may have poorer health, higher expenses for health care, a higher rate of hospitalisations, lower self-efficacy for preventive care practices and compliance to treatment regimens (Ross, 2007). This is true regardless of socio-economic status. People can have years of education and have high functional literacy (reading, writing and numeracy skills), but their health literacy skills can still be limited (Williams, Baker, Parker \& Nurss, 1998). Health literacy skills are not bound to race or age, even though the Interagency Coordinating Council (2002) stated that $80 \%$ of the population aged 60 years and older in the USA alone have insufficient health literacy skills.

Health literacy problems have grown as clinicians and health care system providers expect clients to assume more responsibility for their care at a time when the health system is progressively more fragmented, specialised, complex and technologically sophisticated. The complexity of written and verbal health information and the shortage of health information in languages other than English make it difficult for individuals with low general literacy skills and language differences to communicate effectively in health care (Zagaria, 2006). A majority of printed health education materials, regardless of their topic, require relatively high literacy skills that may not exist among many of their target population (Gal \& Prigat, 2005). In the health care sector, and especially in speech-language pathology, where written information is frequently provided, this may lead to extreme frustration on the part of the client. People with speech, language, visual, hearing and intellectual disabilities experience even greater challenges when they need to apply high-level health literacy skills (Hester \& Stevens-Ratchford, 2009).

Clinicians often overestimate their clients' literacy skills because many clients develop compensatory behaviours. Physical characteristics, such as appearance or the clients' ability to communicate well, are often inaccurate indicators of their literacy level. Even when clinicians have worked with clients for years, they are frequently surprised at the poor reading skills of some of their most articulate clients (Kelly \& Haidet, 2007). While some clinicians only provide verbal information to clients, this approach has the potential to disempower clients, as they are unable to refer back to information when they are at home or may not remember what has been discussed.

Numerous studies on health literacy have been published in various fields, including nursing, paediatrics, psychology, oncology, HIV/AIDS and pharmaceutics. Topics range from ways to improve health literacy to issues around client-provider communication (Bellardie \& Harris, 2008; Chang \& Kelly, 2007; Sanders \& Brosco, 2005). The limited research carried out in speech-language pathology and audiology is striking given that the IOM (2004) identified speaking and listening as areas in need of improvement in health literacy research and intervention. Two studies relevant to these professions were identified, which focused on the readability of educational materials for clients with cleft lip and/or palate and their families, as well as the effects of reader and text variables on understanding of health information in adults (Harris, Fleming \& McDougall, 2003; Kahn \& Pannbacker, 2000). These studies suggest that individuals with communication difficulties and their carers are at an even greater risk of not understanding written materials. There is currently no consensus among health professionals and researchers about which interventions should be incorporated into clinical practice. 
Regardless of the guidelines that have been provided to improve health literacy, the issue of client recall of health care instructions and its effects on the actual outcomes of management is still present.

\section{Client recall: a background}

An important aspect in providing health information to clients, in addition to issues of health literacy, is that of clients' recall of information and instructions after consultations. Recall (both shortand long-term retention) of health information and recommendations are prerequisites for adherence to treatment (Kessels, 2003). This is an important point to consider in light of the widely held assumption that only good health literacy skills are responsible for an increase in adherence to recommendations. It is apparent that the speechlanguage pathology and audiology professions pay minimal attention to issues around clients' memory of health information, even though retention of vast amounts of important information (i.e. diagnosis and recommendations) is critical to treatment outcomes.

Some clients find little logic in what happens during and after consultations. This is because they face the stress of a medical crisis, often without the presence of a significant other person or while in great pain, confusion or depression (Rao, 2007). Forty to $80 \%$ of medical information presented by clinicians is forgotten immediately and nearly half of the information that is actually remembered is incorrect (Kessels, 2003). In light of the above, Parkin and Skinner (2003) found that even when clinicians assume that their clients would recall the health information that was provided, this might not necessarily be the case.
There are various explanations for clients' tendency to forget clinical information. With reference to the clinician: complex language and the provision of too much and disorganised information can make it difficult for a client to recall information. With reference to the client: level of education, stress, anxiety and state of health at the time of consultation; increasing age; perceived unimportance and complexity of information; differences in role expectations regarding rights, duties and responsibilities; and clients 'switching off' as a result of feeling overwhelmed by the emotional impact of the information that they receive may affect recall (North, Cornbleet, Knowles \& Leonard, 1992).

It would seem to be important to address recall of clinical information as well as health-literacy skills during consultations with all clients and especially with the elderly, considering that the general ageing process can create difficulty in recalling clinical information (Kessels, 2003).

Further issues around information exchange and compliance: The South African context

South African SLPs meet clients representing many different language and dialectal groups, and with a range of literacy abilities. These variables can have an influence on the outcomes of health care. South African clients' cultural backgrounds also play an important role in the utilisation of health care (Kagee, 2004). Knowledge of clients' cultural backgrounds is a vital characteristic for any health professional working in the South African context, e.g. some families may prefer traditional health and healing practices to westernised therapy processes (Zhang \& Bennet, 2001). If clients choose not to adhere to treatment prescribed

\section{Table I. Strategies and their advantages/disadvantages in intervention}

\begin{tabular}{ll}
\hline Strategy & Advantages \\
Written materials & Allows recall and revision of important clinical information \\
& Easy to file, store and copy \\
& Appropriate for speedy review and reference \\
Illustrations & Aid understanding of complex information \\
& Very useful for clients with low literacy skills \\
& Looks interesting and eye-catching \\
Telephonic contact & Human contact which can be speedily accessed: best at times of crisis \\
& Useful for reminder calls \\
& Builds a relationship between SLP and client \\
& Mobile phones widely available \\
Audio-visual materials & Does not require literacy skills \\
& Human contact: listening to a voice is reassuring \\
& Durable and relatively inexpensive \\
& Could be translated into any language \\
& Minimally adds to clinician's workload \\
& Can be shared with other significant persons \\
& Cellphones are widely used (over 70\% of South Africans make use of \\
mobile phones) (Internet World Stats, 2010) & Best when recommendations are simple and can be given in point form \\
A tool for quick reminders \\
By using the 'please call me' function, clients can get into telephonic \\
contact with the SLP at no cost \\
Clients use from the privacy of their own home and caregivers do not \\
need to leave the patient unaccompanied
\end{tabular}

Reminders on mobile phones

Personalised clinical information
Serves best as a post-consultation reminder of important points People carry mobile phones with them at all times so reminders would be immediate

\section{Disadvantages}

Only for people who have good literacy skills

Cultural mismatch: some cultures heavily favour oral language, and written materials are less likely to be used as a means for accessing information

A certain level of visual literacy is required

Some information is too abstract and complex to be depicted in illustrations

Clients may not have a telephone of their own (or no airtime) Clients may not be willing to call their clinician

Client and clinician need to share a language

Clients need access to equipment

Recording consultations might inhibit open discussions

Clients need to have good literacy skills and be familiar with the technology

Might be less used by older clients who are not used to this form of communication

Need for good manual dexterity

Not for life-threatening situations as there is too much room

for misunderstandings

Restrictive (often too much information that needs to be conveyed)

Can be time-consuming

Cannot provide practical demonstrations or immediate feedback

Need for good manual dexterity

Restrictive (often too much information that needs to be conveyed)

Not all mobile phones have this function

Additional time is needed to type reminders into mobile phones All mobile phones operate differently so SLPs need to get accustomed to them first

Clinicians find it time-consuming to prepare
Tailored to the unique needs, interests and concerns of the individua More effective in assisting clients adhere to recommendations than general information materials

Unnecessary information is eliminated

Information is more relevant to the individual 
by an SLP because of their cultural beliefs, they might be perceived by the clinician as non-compliant. For example, SLPs may advise parents to stimulate their children's speech and language from an early age, but in some cultures it is not customary to speak to children directly until they reach a certain age (Marfo, 1993).

What may also increase the perception of non-compliance, especially in the South African population, is that there is a culturally determined tendency to accept information non-interactively, without objections or questioning, even when the information may not be entirely understood (Marfo, 1993). This characteristic may be explained by tactics of saving face, different child-rearing practices, perceived unequal power relations between clients and professionals, short duration of consultations and a hesitancy to be open with authoritarian figures such as medical doctors (Cilliers, 2005). Clients might also prefer a rather 'paternalistic style' of client-provider relationships in consultations which means that the health professional is primarily made responsible for the treatment and well-being of the client. However, clients' choice of a more passive role in consultations seems to be reasonable given that they do not have the medical resources or knowledge to reach treatment decisions or the authority to implement them. Regardless of how this 'passivity' or 'noninteractivity' is explained, it raises the prospect of reducing clients' roles in decision making, as well as their success in managing their own health.

South Africa is a linguistically diverse country where 11 official languages are spoken (Big Media Publishers, 2007). Nevertheless, South African public health care is still characterised by a large language divide between clients and clinicians. IsiZulu and IsiXhosa have the highest number of first-language speakers in the country, but the majority of South African health professionals are proficient only in English and/ or Afrikaans (Schwartz, 2004). According to Penn (2007), the majority of health interactions in South Africa are mediated by a third party, and more than $80 \%$ of these interactions between clients, a third party and health professionals take place across linguistic and cultural barriers. Where a language mismatch exists between client and clinician, the presence of a properly trained interpreter can be invaluable. When cross-cultural communication is improved, it may lead to increased client involvement in care, better adherence to treatment regimens, a higher quality of care, and better overall health outcomes (CooperPatrick, Gallo, Gonzales, Thi Vu, Powe, Nelson \& Ford, 1999).

In South Africa, more than 9 million adults are illiterate (UNESCO Institute for Lifelong Learning, 2010). Furthermore, 2.9 - 4.2 million people, i.e. 1 in every 5 South Africans over the age of 20 years, have not received formal education (Nelson Mandela Foundation, 2004). Even though countless South Africans can speak several languages, their literacy skills in all of these may be limited. Many older generations of people who speak African languages and were educated under the apartheid system, as well as many of the younger generations - as a result of the sudden switch to English as the language of learning and teaching (LoLT) in grade 4 - cannot read and write in their mother tongue. Additionally, their literacy skills in English and Afrikaans, which were the only languages allowed for education during the apartheid era (before the riots in 1976), are not sufficient because of inadequacies in the education that was provided under apartheid (Kagee, 2004). Today, despite the efforts of the state and non-government organisations (NGOs), there are still various challenges in the provision of literacy classes that have to be solved (Pretorius, 2004). This means that even when written materials are translated, they may be of little assistance to clients with the above profile.

Long waiting times at clinics or lengthy time lapses between appointments also affect compliance (McDonald, Garg \& Haynes, 2002). Furthermore, clients typically define adherence in terms of their view of good health and they only seek treatment approaches that are (in their view) manageable, tolerable and effective. Many clients only consider medication rather than behavioural regimens to be treatments (Kagee, 2004). This is an important factor to consider in light of the nature of SLP interventions, which typically require behavioural changes and adherence to therapeutic strategies.
Poverty is another variable that affects compliance (Kagee, 2004). Reduced self-efficacy and the demands and stresses of daily survival, work and family life may contribute to the lack of acknowledgement of the importance of complying with treatment regimens.

\section{Practical solutions for improving health literacy, client recall and compliance post consultation}

Clients often forget or misunderstand information if clinicians do not provide additional materials to ensure that when they leave the clinical setting, the information they have is clear, accurate, complete and available for review and discussion with other professionals or family members (Kessels, 2003). There are various studies that tested different interventions (alone and in combination) to improve compliance. These explored, for example, the benefits and concerns related to pictographs (Penn, Frankel, Watermeyer \& Muller, 2009), video/audio recordings (Rao, 2007), short message service (SMS/ text messages) (International Institute for Communication and Development, 2006), telephonic contact/follow-up (Osborne, 2008a), and personalised clinical information (Osborne, 2008b). Almost all the interventions that were found to be effective in long-term health care were complex and included combinations of aspects such as more convenient health care, ongoing counselling, and continual reinforcement of recommendations.

The complexity of the problem of client non-adherence suggests that no single solution is likely to be helpful, and strategies are more functional when combined (Kagee, 2004). Table I provides an outline of the strategies and their advantages/disadvantages in intervention.

Some of the strategies presented in Table I are 'high tech' (i.e. highly advanced and specialised technology is used) and some are 'low tech' (i.e. less advanced technology is involved). While most of the above information aids could be used effectively, not all of them are appropriate for people with complex difficulties, low literacy skills and financial/other resources who live in remote/rural areas. Clients with low health/general literacy skills would typically have fewer means to improve their health literacy skills or review health advice because they cannot effectively access health care materials (Ross, 2007). Clients who live in remote areas cannot attend for frequent therapy which would provide them with a chance to review information - and some clients are more likely to experience difficulties with compliance as a result of poverty. However, examples of strategies which could support these clients in reviewing information, as well as being in contact with their SLP post consultation, are audiovisual materials, telephonic contact and SMS/text messages.

In the presence of limited financial and other resources in the South African health sector, it is important that issues around client adherence are fully understood and compliance is improved in order to enhance the effectiveness of treatments. With more clients having to take charge of their own health management as a result of financial constraints and (contact) time restrictions with health professionals, there is a dire need to maximise compliance (McDonald et al., 2002). Clients need the opportunity to be in contact with their SLP and get feedback when they experience difficulties in treatment. When such difficulties are, for example, associated with dysphagia, potentially severe consequences could result. Health professionals and other stakeholders need to commit to being innovative and empowering their clients to access and use health information through culturally appropriate, cost-effective and user-friendly strategies (Parker, Ratzan \& Lurie, 2003). From an ethical point of view, SLPs might be seen to run the risk of overlooking the principles of non-maleficence and beneficence, if the profession does not invest in means to maximise health literacy and client recall of clinical information in populations that are 'high risk', i.e. groups of individuals who are negatively affected by one or more of the many variables that influence health literacy, client recall and general compliance with treatment. 


\section{Method}

\section{Aims}

The aims of this study were to: (i) trial technology/strategies which may be able to maximise health literacy and client recall of clinical information; and (ii) evaluate the outcomes of the technology/strategies employed from both the SLP's and the client/caregiver's perspective.

\section{Research design}

A single-subject (case-study) design was used with four cases. Traditionally, the focus of single-subject designs is the use of systematic methods for applying interventions and documenting their effects repeatedly in single individuals over a longer period of time (Maxwell \& Satake, 2006). This study only investigated individuals at the first stages of their treatment. This type of design was used nonetheless because it allowed for richness of data in four individual cases. Outcomes of intervention were evaluated by means of semi-structured interviews, subsequent to which data were qualitatively analysed.

\section{Participants}

This study made use of two groups of participants: SLPs and clients/ caregivers. Clients with voice disorders (including laryngectomies), dysphagia or cleft lip and/or palate were the focus of the study. This is because clients' understanding and recall of information relating to these disorders is most critical to compliance with treatment (Fagan, Lentin, Oyarzabal, Isaacs \& Sellars, 2002; Low, Wyles, Wilkinson \& Sainsbury, 2001; Sataloff, 2006). Selection criteria for SLPs were that they had to be practising currently in the greater Cape Town area, and had to have at least 1 year's post-qualification experience in managing at least one of the disorders that formed the focus of the study.

Selection criteria for clients were that they had to have one of the selected disorders or be a caregiver of a child with an unrepaired cleft lip and/or palate or a voice or swallowing disorder. They had to speak a language other than English as their first language because issues which might arise from the language divide between professionals and clients increase the potential for misunderstandings. Clients also had to have a poor socio-economic background (i.e. live in informal settlements or rural areas), as these clients might be more likely to experience difficulties with compliance as a result of poverty (Kagee, 2004). In addition, clients had to have low health and general literacy skills as determined through an informal health literacy screening tool (see Appendix A). It was important to know the level of health/general literacy skills of participants, as clients with low health/general literacy skills typically have fewer means to improve their health literacy skills or review health advice because they cannot understand or read health care materials, thus indicating their need for additional strategies to assist them in this regard. Clients were excluded when they had any additional cognitive, psychological or intellectual disorders, as these were likely to affect their ability to give consent and their ability to express their opinion and perceptions.

One reason for including SLPs as well as clients in this study was because little research has focused on investigating SLPs as well as clients as key role-players in the clinical process (Hester \& Stevens-Ratchford, 2009). Few studies mentioned caregivers and the issues that come with low health literacy and problems in recalling clinical information. For this reason the present study also included the caregivers of children.

Clients and SLPs were recruited at two large public hospitals and a community rehabilitation centre in the Western Cape.

\section{Sampling}

Purposive sampling was used with participants selected based on the researchers' knowledge of their characteristics and the purpose of the study. A total of four participants were needed (i.e. one participant with a voice disorder, one with dysphagia, one with a cleft lip and/or palate and one with a laryngectomy). A small sample size was sufficient as this is an exploratory, qualitative study where the focus was on richness and detail of discussions.

\section{Procedure}

This study was conducted in accordance with the Declaration of Helsinki. The principles that were followed were the principle of respect for people (which includes confidentiality and their autonomy), the principle of non-maleficence/beneficence and the principle of justice. Each participant had to be legally competent, informed and show comprehension before they were invited to sign a consent form voluntarily. Where people could not write, they were able to sign with a thumbprint. The consent forms were read out and explained to them in their preferred language. A trained interpreter was used for this to ensure that the content of the consent form was translated accurately.

A combination of strategies was devised to assist in: (i) maximising health literacy and client recall; and (ii) ensuring an open channel of contact between clients and their SLPs post consultation. Advantages and disadvantages of various strategies (see Table I), information drawn from the literature as well as suggestions by Kessels (2003) and Rao (2007) were considered when deciding on strategies to be trialled. The following strategies were selected to be trialled in combination: $(i)$ audio-recordings in the form of a CD/cassette, (ii) 'please call me' SMS/ text message, and (iii) telephonic follow-up.

The reason for this is that an audio-recording of the consultation in the form of a $\mathrm{CD} /$ cassette is only efficient in assisting health literacy and recall of clinical information, whereas 'please call me' SMS/text message and consequential telephonic follow-up would only serve to allow for routine reminders, enquiries, discussions and feedback post consultation. In South Africa, radio ownership increased from $73 \%$ in 2001 to $76.6 \%$ in 2007 (South Africa Online, 2010) and these days even cheap radios include a $\mathrm{CD}$ player. Even people without their own $\mathrm{CD}$ player are likely to be able to use a neighbour's or relative's CD-player. The 'please call me' SMS function is a standard message (no typing required) that can be sent free of charge to another person's mobile phone in order to alert them of this individual's request for telephonic contact.

Low-tech (e.g. written, illustrative) strategies were not included in this study as these were already used by the SLPs. However where SLPs provided low-tech strategies, the proposed high-tech strategies were always added as a further strategy. Even though only the hightech strategies were focused on in the study, this mix of low-tech and high-tech strategies ensured the provision of visual, auditory and tactile elements in information exchange during and post consultation.

Trialling the use of technology/strategies to maximise health literacy and client recall of clinical information was a key concept to be introduced at a client's first consultation, given that this is typically where health literacy, recall and other variables to compliance determine clients' understanding, eventual recall and resultant adherence to treatment regimens.

Firstly, SLPs were familiarised with the procedures of the three chosen strategies to prevent potential problems from occurring during consultations. SLPs conducted initial assessments according to their routine clinical procedure and made recommendations to their client. Whenever important information and recommendations were to be provided, the SLP gave a signal to the researcher to audio-record that information. When all information was recorded and the consultation was concluded, this audio-recording was given to the client in addition to any low-tech materials that the SLP usually provides. The purpose and use of this recording together with the use of the 'please call me' function of their mobile phone was explained by the researcher. Clients were also given a date for a follow-up appointment (after at least 3 but not more than 6 weeks). The reason for keeping the time interval below 6 weeks was that it has been reported that recall decreases over time even when strategies have been used to improve recall of clinical information and health literacy. This time period gave the client an opportunity to independently manage their own health while using the proposed strategies. The researcher made notes based on information 
from the assessment and recommendations so as to have a record of each participant's treatment regimen for comparisons with the SLP's observations and for later use in data analysis.

\section{Data collection}

The outcomes of the technology/strategies employed during the period between the first consultation and the first follow-up appointment were evaluated from both the SLP's and client's perspective. Firstly, clients were interviewed through short semistructured interviews to probe more deeply into their experiences and views on the effectiveness of the strategies in assisting with understanding and recalling clinical information. Subsequently, a questionnaire using a Likert scale and open-ended questions as well as a subsequent semi-structured interview was conducted with SLPs. The purpose of the questionnaire was to assist in organising data and further in-depth discussions while allowing SLPs time to think about their responses. The subsequent interview gave the researcher an opportunity to probe more deeply into the positive or negative experiences reported by the SLP after having used the strategies.

\section{Analysis}

An immersion/crystallisation style was used when analysing the data. For this purpose, data of SLP and client individual interviews were transcribed. Patterns that emerged from the data had to be identified and matched with patterns in the literature review/other scientific knowledge so as to enhance internal validity. Themes suggested by Ammenwerth, Brender, Nykänen, Prokosch, Rigby and Talmon (2004) were considered, adapted and combined to form five themes against which the data were analysed. The themes were:

1. Improvement of knowledge and recall of medical information (long and short term).

2. Satisfaction related to the value that is placed on the strategies or the extent to which the participants found them to be helpful.

3. Is the combination of the strategies usable in the intended environment and for the intended purpose? If not, what are SLPs' and clients' attitudes towards using the strategies in future and suggestions on improvements?

4. Do users need more training and guidance in order to use the strategies appropriately?

5. Possible effects that the combination of these strategies has on structural or process quality (e.g. time saving, clinical workflow).

\section{Results}

\section{Case study 1 (client with a laryngectomy)}

In this case study, strategies that were used included counselling, illustrations, audiorecording, the option of a 'please call me' SMS/text message and telephonic followup. The client reported that she forgot some details when she eventually arrived at home, which is when she used the audio-recording to refresh the information in her mind, thus indicating her need for a strategy to review information once she was at home. She also found it helpful to listen to a voice during the day when she was alone at home, to review information and for reassurance. She explained:

\section{P1: During the weeks when I was so alone, I would sit and I put the tape on and just listen. \\ R: So was it also just that you could listen to the speech therapist's voice? P1: Yes.}

Nevertheless, this particular client continued to have poor recall and health literacy skills, possibly related to emotional aspects, poor social factors and additional stressors of daily life. She spent much of her energy on longing for her previous life and coming to terms with her present situation, rather than performing self-care and managing her own health and future through the use of strategies. She felt hopeless and confused, which may have further clouded her judgement and prevented her from effectively managing her own health.

The client also struggled to deal with her partner's rejection and reluctance to accept her condition. This agrees with a finding by Bunning (2004), who explained that knowing what a child or partner was like before being affected by a disability can make it difficult for significant others to accept the 'new' person, which in turn makes it more difficult for the client to be enthusiastic about complying with treatment regimens.

It is not known whether or not the client would have been better equipped to manage her own health after she had time to deal with her situation, regain confidence and 


\section{Table III. Case study 2}

\begin{tabular}{|c|c|c|c|c|c|c|c|}
\hline Case number & $\begin{array}{l}\text { Speech-language } \\
\text { pathology service } \\
\text { provided for }\end{array}$ & $\begin{array}{l}\text { Literacy } \\
\text { Skills }\end{array}$ & $\begin{array}{l}\text { Resides } \\
\text { in }\end{array}$ & $\begin{array}{l}\text { Home } \\
\text { language }\end{array}$ & Employment & $\begin{array}{l}\text { Living } \\
\text { situation }\end{array}$ & $\begin{array}{l}\text { Reported health } \\
\text { literacy skills }\end{array}$ \\
\hline $\begin{array}{l}\text { Case } 2 \\
\text { (caregiver aged 33) }\end{array}$ & $\begin{array}{l}\text { Provision of information, } \\
\text { counselling and feeding } \\
\text { recommendations for } \\
\text { premature infant with } \\
\text { cleft palate }\end{array}$ & $\begin{array}{l}\text { No English literacy } \\
\text { skills, but proficient } \\
\text { in Somali }\end{array}$ & Urban area & Somali & Unemployed & $\begin{array}{l}\text { Lived in a small house } \\
\text { with the husband's } \\
\text { brother and his family }\end{array}$ & $\begin{array}{l}\text { Able to ask important } \\
\text { questions during } \\
\text { consultations with } \\
\text { only an occasional } \\
\text { misunderstanding }\end{array}$ \\
\hline Treating SLP & $\begin{array}{l}\text { Years of experience in } \\
\text { the field and in working } \\
\text { in public health }\end{array}$ & $\begin{array}{l}\text { Strategies that are } \\
\text { usually employed }\end{array}$ & & & $\begin{array}{l}\text { Home } \\
\text { language }\end{array}$ & Employed at & \\
\hline Female & 14 & $\begin{array}{l}\text { - Verbal feedback } \\
\text { - Counselling } \\
\text { - Information brocl } \\
\text { - Provides work an } \\
\text { phone number }\end{array}$ & $\begin{array}{l}\text { hures and pan } \\
\text { occasionally }\end{array}$ & $\begin{array}{l}\text { lets } \\
\text { obile }\end{array}$ & English & Tertiary hospital & \\
\hline
\end{tabular}

practise using the combined strategies to her advantage. The researchers and the SLP wondered whether or not the effectiveness of the combined strategies might be realised at a later stage.

Discussions with the SLP continued to investigate what could be done differently for clients with laryngectomies who are illiterate, come from rural areas and have a disadvantaged socio-economic background. The SLP saw the value of the combined strategies, but she was aware that they might not be a single universal technique to use with any client. She explained:

With laryngectomies I don't really know. I think if they don't have easy access because they often need medical attention ... You know none of the strategies might be superb ... because it's not just depending on them. It's not like a dysphagia where you say; remember to put your head down when you swallow! Ahm ... there can be infections, there can be small stomas, there can be ... prostheses fall out and then what you've taught them is just for if everything is fine. If everything isn't fine they need medical attention so ...

Therefore, no single strategy might be effective because there will always be unforeseen problems that need immediate attention from various professionals. This highlights the need for regular contact - face to face or through SMS/text message or telephone.

Finally, it was observed that the SLP was caring and spoke to the client in a manner which was clear and in accordance with the client's level of language, a factor which was viewed to play a significant role in this case.

\section{Case study 2 (caregivers of a child with cleft palate)}

In this case study, strategies that were used were counselling, an audiorecording and the option of a 'please call me' SMS/text message and telephonic follow-up. Management in this case was effective; determined by the SLP's and the client's accounts, as well as their ability to follow treatment guidelines. However, it was not clear whether the success was due to: $(i)$ the combined strategies being of real assistance; (ii) the caregivers being insightful and motivated from the beginning; or (iii) a combination of both. Nevertheless, the clients did not have any written information to refer to, which suggests that the combined strategies were important when clients wanted to review information. In addition to being able to review information, the caregivers felt it was also beneficial to share information with others. The mother reported that her neighbour had commented on the use of the audio-recording as follows:

She say it's nice, doctor give to you the $C D$, reminding you every time your baby ... they say yes it's nice talk (not audible).

This case provided a contrast to case study 1 . In the first case, the client experienced socio-emotional difficulties that impacted on her compliance, but in this case the parents were practical and pro-active about their child's future health.
The SLP saw the value of the combined strategies but had concerns about their future use. Among the reasons for this concern was the issue of interpreters and that she felt the strategies were not practical because they would take time and she would have to invest in a system that would record and burn CDs. She would also always have to find a quiet room, which is not easy in a hospital, and it would require a lot of additional planning which would be more of a burden than of assistance. She further explained that these particular clients might also struggle with making sense of the information later at home, when it is out of context. Alternatively, the SLP suggested that only a mobile phone number instead of a CD be provided as it was quicker and easier, there was less room for misunderstandings and no need for additional expensive equipment to be bought. However, if clients do not contact the SLP to ask for clarifications, they might misunderstand or not remember information and implement the wrong feeding technique.

In the questionnaire, this SLP indicated that there is a difference between disorders and the need for the combined strategies, which is similar to what the SLP in case study 1 suggested. This SLP explained that in cases of voice clients for example, CDs with clinical information would be more practical where principles of therapy are more generic and you can easily record and make sense of them. Another example that she provided was that of articulation therapy for children, where she could record a session and the caregiver could follow the whole programme at home. In cases of clients with dysphagia or laryngectomies, this is more difficult as disorders are more acute or critical, and hands-on guidance, as well as practical demonstration, is needed. In these cases, visual tools like a video-recording would probably be more appropriate because information is presented visually and in context, whereas an audiorecording might be less clear especially if out of context. However, she explained that having to create video-recordings might be just as impractical as audio-recordings. It would initially take additional consultation time and she would have to invest in a system that would record videos or DVDs.

This question of whether this specific combination of strategies would perhaps be more effective with disorders that are less severe, complex and acute stood out after having analysed these two case studies.

\section{Case study 3 (adult client with dysphagia)}

In this case study, strategies that were used were counselling, illustrations, written information in point-form, an audio-recording, the option of a 'please call me' SMS/text message and telephonic follow-up.

One advantage of the combined strategies which stood out most in this case study was that the strategies and materials provided clients with an opportunity to comprehend and recall aims and rationales for treatments. The SLP in this case explained that:

... the client seemed like he had more resources to work with, he was more motivated to do his task ... he was more motivated because 


\section{Table IV. Case study 3}

\begin{tabular}{|c|c|c|c|c|c|c|c|}
\hline Case number & $\begin{array}{l}\text { Speech-language } \\
\text { pathology service } \\
\text { provided for }\end{array}$ & $\begin{array}{l}\text { Literacy } \\
\text { skills }\end{array}$ & $\begin{array}{l}\text { Resides } \\
\text { in }\end{array}$ & $\begin{array}{l}\text { Home } \\
\text { language }\end{array}$ & Employment & $\begin{array}{l}\text { Living } \\
\text { situation }\end{array}$ & $\begin{array}{l}\text { Reported health } \\
\text { literacy skills }\end{array}$ \\
\hline $\begin{array}{l}\text { Case } 3 \\
\text { (male aged 41) }\end{array}$ & $\begin{array}{l}\text { Was educated about } \\
\text { reasons for swallowing } \\
\text { difficulties and received } \\
\text { recommendations for } \\
\text { feeding as well as exercises } \\
\text { for dysarthria }\end{array}$ & $\begin{array}{l}\text { Finished school } \\
\text { at grade } 4 . \\
\text { Says he has } \\
\text { difficulty reading } \\
\text { complex text }\end{array}$ & $\begin{array}{l}\text { Informal } \\
\text { settlement }\end{array}$ & Afrikaans & Unemployed & $\begin{array}{l}\text { His wife, a domestic } \\
\text { worker, was the sole } \\
\text { provider of the family } \\
\text { (with two children). } \\
\text { They lived in informal } \\
\text { housing with no running } \\
\text { water or electricity. } \\
\text { During the day, the } \\
\text { client's sister took care } \\
\text { of him. His wife sometimes } \\
\text { pushed the client in his } \\
\text { wheelchair more than } \\
5 \text { km to the clinic. } \\
\text { When they had enough } \\
\text { money, they would hire } \\
\text { a taxi. The only mobile } \\
\text { phone which they owned } \\
\text { had been lost recently. } \\
\text { The sister's mobile phone } \\
\text { was therefore used in } \\
\text { cases of emergency }\end{array}$ & $\begin{array}{l}\text { They explained that } \\
\text { they occasionally } \\
\text { had difficulties } \\
\text { understanding } \\
\text { some written or } \\
\text { verbal information }\end{array}$ \\
\hline Treating SLP & $\begin{array}{l}\text { Years of experience in the } \\
\text { field and in working in } \\
\text { public health }\end{array}$ & $\begin{array}{l}\text { Strategies that are } \\
\text { usually employed }\end{array}$ & & $\begin{array}{l}\text { Home } \\
\text { language }\end{array}$ & Employed at & & \\
\hline Female & 2 & $\begin{array}{l}\text { - Illustrations } \\
\text { - Keeping aims at } \\
\text { - Repetitions } \\
\text { - Using teach-bac } \\
\text { - Written instruct } \\
\text { caregivers }\end{array}$ & $\begin{array}{l}\text { minimum } \\
\text { method } \\
\text { ons for }\end{array}$ & $\begin{array}{l}\text { English \& } \\
\text { Afrikaans }\end{array}$ & $\begin{array}{l}\text { Community } \\
\text { clinic }\end{array}$ & & \\
\hline
\end{tabular}

he could take ownership and responsibility for his therapy because he had something in his hand you know to look back at and to refer back to all the time. So for me I feel that now, where you actually give the client a tape or you give the client the page, then it's them taking the responsibility and saying; ok I need to work on my thing now. So I think it's quite beneficial because if the clients leave without something, then I often find that they forget everything and they don't take that responsibility.

When asked whether they would have still forgotten even in the presence of having the illustrations and the recommendations in pointform, the clients explained:

The tape provides more clarity. Look we got the exercises but this is just a picture and the picture cannot speak ... but the patient and the speech therapist speak with each other. She explains what is going on and he follows her advice. There is an understanding between the two because what is discussed in the session is recorded on here. It is something that happens in real-time.

Furthermore, the couple felt that access to 'please call me' SMS/text message and regular telephonic contact would have been most beneficial initially when the client had first come out of the hospital. He had experienced various difficulties with his speech in addition to frequent aspiration and it would have made them feel safer knowing that they could receive immediate support when needed. Here, it is indicated that at the initial stages of treatment, clients' need for professional support and empowering strategies to manage their health is vital.

The SLP thought the combined strategies were appropriate for all disorders listed; namely dysphagia, voice disorders, laryngectomy and cleft lip and/or palate management. All these disorders require the therapist to obtain regular feedback from clients because the status of these disorders frequently changes and new difficulties arise. For example, there might have been spontaneous recovery or regression in the client's therapeutic process. She explained:
Especially with the dysphagia clients, I noticed that they often recover quickly or they have different problems ... so I feel they need to be monitored closely because maybe on the first day you see that your aims are specific and then the next time that you see them the aims are different because ... there has been spontaneous recovery, there has been some regression. So, in order for my therapy process to be guided, I need to get that constant feedback from the client all the time.

When aims become obsolete in the event of regression or improvement of a disorder, clients can review the information, realise that it is not sufficient any more, and become conscious of their need to contact their SLP to solve current problems.

She agreed that this is also where 'please call me' SMS/text message and subsequent telephonic follow-up become central. She was worried that when this does not occur, clients become overwhelmed by the changes and resultant needs associated with their disorders if not followed-up immediately.

... I feel worried that their disorder might change and they get lost in the system and then who does the follow-up, if we aren't there to do the follow-up for them? So it becomes a critical issue.

This adds to findings by Zagaria (2006) who found that, when lacking appropriate support, clients become overwhelmed when having to manage their own health and by the pressures of achieving therapy goals. The above perspective provides a reason why these strategies would be effective in the treatment of the disorders focused upon in this study, as well as in any other disorders treated in speech-language pathology. Overall, the SLP was enthusiastic when asked whether or not she felt that she would like to routinely use the combined strategies. She explained:

... I would definitely use the strategy if I had something set up here at the centre and say for instance they gave me this in a budget and they gave me the resources to be able to do it, then I would have done it. 
Even though the SLP saw the value of the combined strategies, she had some concerns which would have to be addressed. For example, she emphasised that she would have to set up a system for recording information that was not intrusive to the client, and instead of having the 'please call me' SMSs come to her personal mobile phone, have a computer system at the centre that would receive SMSs/text messages. She explained that this is important as she works in a team setup and clients frequently have difficulties that have to be addressed by a team of experts. This further emphasised the usefulness of the 'please call me' SMS/text message and telephonic follow-up when clients are managed by various health professionals.

The SLP in this case study was noticeably more positive, motivated and enthusiastic about implementing the combined strategies in future compared with the therapists in the first and second case study.

\section{Case study 4 (adult client with a voice disorder)}

In this case study, strategies that were used were counselling, written information in point form, an audio-recording and the option of a 'please call me' SMS/text message and telephonic follow-up. The client reported that even though she had understood everything once she had left the consultation for the first time, she felt the need to listen to the audio-recorded information frequently because it contained further details than the written information provided for her. She explained:

You know I got all this information on a piece of paper but it is better for me to put on the tape and listen to it ... The additional detail to information that is on the tape is helpful yes.

The client also found that the combined strategies gave her the opportunity to manage her voice disorder on a long-term rather than a once-off basis. As a result of dedicating time, sitting down and following written instructions while listening to the cassette, she may have felt more as though she was doing a whole treatment session rather than just reading a sheet of written clinical information in point-form which could be less engaging after a period of time, or it might not be appropriate to her learning style (e.g. she might prefer a range of audio, visual or pictorial materials).

One SLP opinion that stood out from this discussion was that, irrespective of the presenting disorders, clients (at the institution where she works) all have low socio-economic backgrounds and similar education levels, which is why the combined strategies would serve them all in maximising health literacy skills, recall and compliance and not just clients with selected disorders. The SLP explained:
... they will use their last money because they are concerned about their health ... so you can't come and waste their time. You need to give as much as you can especially for the people who live far... They need to leave feeling that it was worth that R60 or whatever that they gave out.

Health professionals have to make every effort to ensure that clients understand their treatment regimen and can manage their own health when they return home so that motivation and treatment compliance can be improved. This has also been mentioned by most therapists in this study which confirms SLPs' awareness of the importance of these variables.

The SLP raised some concerns that would have to be addressed if the combined strategies were to be used in future: for example, $(i)$ that clients might not have the insight to realise that they need to question certain aspects of therapy or acknowledge their need to contact the therapist for assistance; and (ii) when clients have a problem, they usually consult someone in their community who they regard as being wise (e.g. a traditional healer or a community leader), which could ultimately result in the combined strategies being ineffectual as they would not be used.

The researcher and the SLP agreed that, should the combined strategies be implemented at an institution, it would allow people to become used to their presence and they might use a combination of strategies or just some part of them more readily and effectively. She also highlighted that it is important to understand that cultural influences are particularly strong in rural areas. In this case, the SLP would have to investigate a client's needs and preferences after which a joint decision could be made on a strategy which allows for regular contact with the SLP and also maximises that client's health literacy, recall and resultant compliance to treatment.

Once more, this SLP was noticeably more positive, motivated and enthusiastic about implementing the combined strategies in future compared with the therapists in the first and second case studies.

\section{Discussion}

Management of three out of the four case studies was judged to be effective as determined by the SLPs' and the clients' accounts, as well as their ability to follow treatment guidelines. Various factors played a role in each particular case, but subjective opinions largely showed that the strategies assisted clients in maximising health literacy and client recall, while ensuring an open channel of contact between clients and their SLPs post consultation.

Table V. Case study 4

\begin{tabular}{|c|c|c|c|c|c|}
\hline Case number & $\begin{array}{l}\text { Speech-language } \\
\text { pathology service } \\
\text { provided for }\end{array}$ & $\begin{array}{l}\text { Literacy } \\
\text { skills }\end{array}$ & $\begin{array}{l}\text { Resides } \\
\text { in }\end{array}$ & $\begin{array}{l}\text { Home } \\
\text { language }\end{array}$ & Employment \\
\hline $\begin{array}{l}\text { Case } 4 \\
(\text { female aged } 58)\end{array}$ & $\begin{array}{l}\text { Counselling for the } \\
\text { prevention of vocal } \\
\text { abuse and misuse }\end{array}$ & $\begin{array}{l}\text { Moderate literacy } \\
\text { skills in English } \\
\text { and Afrikaans }\end{array}$ & $\begin{array}{l}\text { Urban area } \\
\text { in a house }\end{array}$ & Afrikaans & $\begin{array}{l}\text { Employed as } \\
\text { a tea-lady }\end{array}$ \\
\hline Treating SLP & $\begin{array}{l}\text { Years of experience } \\
\text { in the field and in } \\
\text { working in public } \\
\text { health }\end{array}$ & \multicolumn{2}{|c|}{ Strategies that she usually uses } & $\begin{array}{l}\text { Home } \\
\text { language }\end{array}$ & Employed at \\
\hline Female & 8 & \multicolumn{2}{|c|}{$\begin{array}{l}\text { - Written instructions } \\
\text { - Teach-back method } \\
\text { - Informing caregivers and } \\
\text { significant others about the } \\
\text { client's disorder and treatment }\end{array}$} & English & Tertiary hospital \\
\hline
\end{tabular}


Clients in all four case studies listened to the audio-recorded information and were aided through being able to review the detailed conversation. Furthermore, clients in case studies 1 and 2 found listening to a voice more reassuring, personal and human compared with written information. These are important findings, as much of the literature usually provided to clients goes unread (Kessels, 2003).

As described by Osborne (2008a), some participants were reluctant to get into telephonic contact. In some cases there were technical issues, whereas in other cases participants just did not feel the need to contact their SLP even though their follow-up appointment showed that it would have been helpful had they contacted their SLP for guidance on selected issues.

In most cases, provision of the combined strategies was time well spent, especially when clients were at 'high risk' and had ready access to the equipment needed to utilise the strategies. Some SLPs indicated the cost-effectiveness of using the combined strategies in that if clients were to start using these strategies early in their treatment process, recovery could be achieved more quickly as clients can review information in their own time and through regular telephonic contact, clients can be assisted continually, not just at follow-up appointments. In addition, the strategies would not require expensive equipment. For example, most professionals have access to the Internet and generally clients have access to phones, mobile phones and CD players (Kreutzer, 2009). Cassettes, which were used in some of the case studies, are rapidly becoming outdated, which is why CDs/DVDs, widely and relatively inexpensively available in South Africa, would be more appropriate. An initial investment would need to be made for a portable CD burner and audio-recorder. However, this equipment should be useful for many other tasks in hospitals/clinics. SLPs would need time to develop the best equipment and procedure (through clinical trial and error) so that they could make informed and effective decisions for when and how to use these strategies without them becoming an added burden.

All the effort would be a waste of time if interpreters are not readily available, both at times of audio-recordings and during telephonic follow-up. Furthermore, SLPs made it clear that the combined strategies are not a blanket technique for all clients. Clients would need to $(i)$ have access and experience in using the equipment needed to utilise the combined strategies; and (ii) be insightful, motivated and have enough problem-solving skills to use the strategies effectively. A client's stage of recovery and resulting coping skills, as well as cultural influences and familial circumstances, are also variables that have to be considered as possibly interfering with effective use of strategies by clients.

When considering all participants' opinions, it became clear that the clients' overall experience and value of the combined strategies, was positive and that without them they would have had difficulties in dealing with the information and managing their health post consultation. However, at times it seemed that clients would be satisfied with any strategy which is novel and makes them feel confident in managing their own (or their child's) health.

SLPs were generally positive about the combined strategies. SLPs of case studies 3 and 4 were noticeably more positive, motivated and enthusiastic about implementing the combined strategies in future than the therapists in the first and second case studies. It was not clear whether this was because they were younger and had spent less time in practice than the former SLPs, who were more wary of the challenges faced and the role of the combined strategies. Therapists who have been in the field for many years have settled perceptions about the most appropriate information exchange in practice. They have had much experience of clients' lack of adherence to treatment regimens, despite their efforts to assist clients in complying. On the other hand, younger therapists may like to experiment with various avenues of information exchange with their clients, which could be a reason for their enthusiasm about the combined strategies.

\section{Clinical implications}

SLPs need to be aware that motivation and insight may impact considerably on compliance and treatment outcomes - with or without strategies - and therefore should also consider ways of maximising these. SLPs would have to investigate obstacles to compliance, a clients' stage of recovery (and resultant coping skills), personal situations, learning styles and ways of thinking and problem-solving when wanting to maximise information uptake. Subsequently, both parties could jointly decide on a strategy that allows for regular contact with the SLP and also maximises that client's health literacy and recall post consultation. It would be inappropriate to expect that the combined strategies could solely assure that health literacy and recall are maximised. A caring and supportive therapist is necessary for clients to feel motivated and confident to take control of the management of their health. At the same time clients have to be insightful enough to realise when they need assistance and make contact so that no time is wasted and their condition does not deteriorate. Therefore, when SLPs identify a client who is at 'high risk' for non-compliance, they should initially contact the client to encourage recall and problem solving and at the same time teach the client to initiate contact.

SLPs need to acknowledge that any strategy which makes clients feel confident because they are equipped and thus empowered to manage their (or their child's) health is vital when wanting to assure continued service delivery and success in treatment (Moon, Cheng, Patel, Baumhaft \& Scheidt, 1998).

These combined strategies might not only have different functions and possibly different outcomes for different disorders, but they might also have different outcomes at different stages of a client's recovery. The strategies should be adapted or provided as they have been proposed, to most clients who seek speech-language pathology treatment for any disorder, especially those with low literacy skills and who do not have the financial means to attend frequent therapy sessions or contact their SLP telephonically.

A preliminary framework (see Appendix B) could serve as a decisionmaking framework for SLPs who want to maximise health literacy, recall and compliance in clients. This framework is preliminary because it only focuses on the disorders and settings from this preliminary study. Future research exploring the combined strategies for other disorders in different settings would assist in making this framework more holistic and complete. Future research should also investigate a larger more representative sample including a range of disorders in various settings across the country and at different stages of a client's recovery.

Clients from high socio-economic backgrounds with well-developed literacy skills may be affected by some of the variables to compliance that have been identified in this study and in the literature. Participants with good health literacy skills should be included in future studies to identify the needs and issues that play a role in their compliance. Further research topics could include $(i)$ whether or not the issues that these clients experience are similar or different to those of clients with low health literacy skills; and (ii) which strategies could be of assistance to their compliance with speech-language pathology treatments.

\section{Limitations}

This study was limited in that the long-term effectiveness of the combined strategies was not explored. Ideally these strategies should have been used with clients right through their treatment process. Another procedure that could have been conducted was to perform a quiz with clients right after the consultation and then again before the next follow-up appointment to generate objective data that would show (i) how much information the client initially understood and recalled; and (ii) how much information they could recall and describe after having used the strategies at home. 


\section{Conclusion}

This study provided insight into various strategies that are available for information exchange. Almost all the interventions that aim to improve compliance are complex (Kagee, 2004). There is no one solution or universal tool for maximising health literacy and recall in the presence of various factors that impact the utilisation of the combined strategies and compliance. It depends on each client and their treating SLP which aspect of the combined strategies they see fit to use.

Future challenges for SLPs will be to effectively manage barriers such as clients' varying levels of literacy, motivation, insight and problemsolving skills; the lack of support from families; the need for trained interpreters; and lack of funds and resources. It is important that SLPs not only consider health literacy and client recall issues in their everyday practice but that this profession with its methods of analysis and sensitivity to the communication process can unquestionably make a contribution to health literacy and client recall in general, particularly in South Africa with its disease burden and where there are many barriers to care. The cycle of low health literacy and education levels, poor income and health and the inaccessibility to information technology can only be broken if information is brought to those who are underserved.

\section{Acknowledgements}

Acknowledgements to all the participants who volunteered their time, and especially to the therapists who assisted in finding clients. Thanks also to Martha Geiger and Vivienne Norman for comments on an earlier draft.

\section{References}

Ammenwerth, E., Brender, J., Nykänen, P., Prokosch, H. U., Rigby, M., \& Talmon, J. (2004). Visions and strategies to improve evaluation of health information systems. Reflections and lessons based on the HIS-EVAL workshop in Innsbruck [Electronic Version] International Journal of Medical Informatics, 73, 479-491.

Bellardie, H. H., \& Harris, A. M. P. (2008). What do parents of newborn babies with cleft lip and/or palate want to know? Does the leaflet from the Cleft Lip and Palate Unit at Red Cross Children's Hospital fulfil these needs, and what is its grading for 'readability'? South African Journal of Child Health, 2(3), 125-128.

Big Media Publishers. The languages of South Africa. Retrieved on 5 February 2008 from http://www.southafrica.info/ess_info/sa_glance/demographics/language.htm

Bunning, K. (2004). Speech and language therapy intervention: Frameworks and processes. London: Whurr Publishers.

Chang, M., \& Kelly, A. E. (2007). Patient education: Addressing cultural diversity and health literacy issues. Urologic Nursing, 27(5), 411- 417.

Chew, L. D., Bradley, K. A., \& Boyko, E. J. (2004). Brief questions to identify patients with inadequate health literacy [Electronic Version]. Special Articles: Health Literacy and Family Medicine, 36(8), 588-594.

Cilliers, B. (2005). Talking about medical talk: Exploring experiences regarding communication in HIV/AIDS health care in a tertiary health care setting. Unpublished master's thesis, University of Cape Town.

Cooper-Patrick, L., Gallo, J. J., Gonzales, J. J., Thi Vu, H., Powe, N. R., Nelson, C., \& Ford, D E. (1999). Race, gender, and partnership in the patient-physician relationship [Electronic Version]. Journal of the American Medical Association, 282(6), 583-589.

Fagan, J. J., Lentin, R., Oyarzabal, M. F., Isaacs, S., \& Sellars, S. L. (2002). Tracheoesophageal speech in a developing world community [Electronic Version]. Archives of Otolaryngology - Head \& Neck Surgery, 128, 50-53.

Gal, I., \& Prigat, A. (2005). Why organisations continue to create patient information leaflets with readability and usability problems: an exploratory study. Health Education Research, 20(4), 485-493.

Harris, J. L., Fleming, V. B., \& McDougall, G. J. (2003, November). Effects of text and reader variables on understanding health information. Poster presentation at the Annual Convention of the American Speech-Language-Hearing Association, Chicago.

Hester, E. J., \& Stevens-Ratchford, R. (2009). Health literacy and the role of the speechlanguage pathologist. American Journal of Speech-Language Pathology, 18, 180-191.

Institute of Medicine. (2004). Health literacy: A prescription to end confusion. Retrieved on 2 February 2008 from http://www.iom.edu/Object.File/Master/19/736/health\%20 literacy\%20final.pdf

Interagency Coordinating Council. (2002). Adult basic and literacy education. (A report on health literacy.) Retrieved on 4 April 2008 from http://www.able.state.pa.us/able/lib/able/ HEALTHLIT_2002.pdf

International Institute for Communication and Development (IICD). (2006). SMS technology for TB treatment. Retrieved on 28 March 2008 from http://www.comminit. com/en/node/147683

Internet World Stats. (2010). South Africa - mobile market, overview and statistics report. Retrieved 22 April 2008, from http://www.internetworldstats.com/af/za.htm
Kagee, A. (2004). Treatment adherence in South African primary healthcare [Electronic Version]. South African Family Practice, 46(10), 26-30.

Kahn, A., \& Pannbacker, M. (2000). Readability of educational materials for patients with cleft lip and palate and their families [Electronic Version]. American Journal of SpeechLanguage Pathology, 9, 3-9.

Kelly, P. A., \& Haidet, P. (2007). Physician overestimation of patient literacy: A potentia source of healthcare disparities. Patient Education and Counseling, 66, 119-122.

Kessels, R. P. C. (2003). Patients' memory for medical information [Electronic Version]. Journal of the Royal Society of Medicine, 96(5), 219-222.

Kreutzer, T. (2009). Generation mobile: Online and digital media usage on mobile phones among low-income urban youth in South Africa. Unpublished master's thesis, University of Cape Town.

Low, J., Wyles, C., Wilkinson, T., \& Sainsbury, R. (2001). The effect of compliance on clinical outcomes of patients with dysphagia on videofluoroscopy [Electronic Version] Dysphagia, 16, 123-127.

Marfo, K. (1993). Families in non-western cultures: Africa as a case example. In J. L. Paul \& R. J. Simeonsson (Eds.), Children with special needs: Family, culture and society (2nd ed. pp. 147-163). Fort Worth: Harcourt-Brace College Publishers.

Maxwell, D. L., \& Satake, E. (2006). Research and statistical methods in communication sciences and disorders. Canada: Thomson Delmar Learning.

McDonald, H. P., Garg, A. X., \& Haynes, R. B. (2002). Interventions to enhance patient adherence to medication prescriptions: A scientific review [Electronic Version]. Journal of the American Medical Association, 288(22), 2868-2879.

Moon, R. Y., Cheng, T. L., Patel, K. M., Baumhaft, K., \& Scheidt, P. C. (1998). Parental literacy level and understanding of medical information [Electronic Version]. Pediatrics, $102(2), 25-30$

Nelson Mandela Foundation. (2004). How far have we come? Reflections from the first 10 years of basic education transformation. Retrieved 2 February 2008 from http://www. polity.org.za/attachment.php?aa_id $=2848$

North, N., Cornbleet, M. A., Knowles, G., \& Leonard, R. C. (1992). Information giving in oncology: A preliminary study of tape-recorder use [Electronic Version]. British Journal of Clinical Psychology, 31, 357-359.

Osborne, H. (2008a). Making the phone a useful tool for working with patients. OnCall Magazine: An online magazine for healthcare professionals. Retrieved 2 August 2008 from http://www.healthliteracy.com/article.asp?PageID=7849

Osborne, H. (2008b). In other words ... how memory affects health understanding. OnCall Magazine: An online magazine for healthcare professionals. Retrieved 2 August 2008 from http://www.healthliteracy.com/article.asp?PageID=7849

Parker, R. M., Ratzan, S. C., \& Lurie, N. (2003). Health literacy: A policy challenge for advancing high-quality healthcare [Electronic Version]. Health Affairs, 22(4), 147.

Parkin, T., \& Skinner, T. C. (2003). Discrepancies between patient and professionals recall and perception of an outpatient consultation [Electronic Version]. Diabetic Medicine, 20, 909-914

Penn, C., Frankel, T., Watermeyer, J., \& Muller, M. (2009). Informed consent and aphasia Evidence of pitfalls in the process. Aphasiology, 23(1), 3-32.

Penn, C. (2007). Factors affecting the success of mediated medical interviews in South Africa [Electronic Version]. Current Allergy \& Clinical Immunology, 20(2), 66-72.

Pretorius, L. (2004). An introduction to adult literacy in the African context [Electronic Version]. Language Matters: Studies in the Languages of Southern Africa: Adult Literacy in the African Context: Special Issue, 35(2), 343-347.

Rao, P. R. (2007, May). Health Literacy: The cornerstone of patient safety [Electronic Version]. The ASHA Leader, 8-21.

Ross, J. (2007). Health literacy and its influence on patient safety [Electronic Version] Journal of PeriAnesthesia Nursing, 22(3), 220-222.

Sanders, L., \& Brosco, J. (2005). Low caregiver health literacy: A risk factor for child access to a medical home [Electronic Version]. Pediatric Academic Society, 57, 2772.

Santo, A., Laizner, A. M., \& Shohet, L. (2005). Exploring the value of audiotapes for health literacy: A systemic review [Electronic Version]. Patient Education and Counseling, 58, 235-243.

Sataloff, R. T. (2006). Voice impairment, disability, handicap and medical/legal evaluation. In J. S. Rubin, R. T. Sataloff \& G. S. Korovin (Eds.), Diagnosis and treatment of voice disorders (3rd ed., pp. 319-327). San Diego: Plural Publishing.

Schwartz, T. (2004). Communication in health within the South African context: Curren practices employed across three levels of health care. Unpublished master's thesis, University of Cape Town.

South Africa Online. (2010). Communications. Retrieved 10 May 2010 from http://www. southafrica.co.za/about-south-africa/science-and-technology/communications/

UNESCO Institute for Lifelong Learning. (2010). Adult Literacy and Skills Training Programme (ALSTP) Country Profile: South Africa. Retrieved 8 June 2010 from http:// www.unesco.org/uil/litbase/?menu=4\&programme $=52$

Williams, M. V., Baker, D. W., Parker, R. M., \& Nurss, J. R. (1998). Relationship of functional health literacy to patients' knowledge of their chronic disease [Electronic Version] Archives of Internal Medicine, 158, 166-172.

Yin, H. S., Forbis, S. G., \& Dreyer, B. P. (2007, August). Health literacy and pediatric health [Electronic Version]. Current Problems in Pediatric Adolescent Healthcare, 37, 258-286.

Zagaria, M.E. (2006). Low Health Literacy: A Safety Concern Among the Elderly [Electronic Version]. U.S. Pharmacist, 31,28-34. Retrieved 8 June 2010 from http://www. uspharmacist.com/content/d/senior\%20care/c/11540/

Zhang, C., \& Bennet, T. (2001). Multicultural views of disability: Implications for early intervention professionals [Electronic Version]. Infant-Toddler Intervention: The Transdisciplinary Journal, 11, 143-154. 


\section{Appendix A. Informal health literacy screening tool adapted from Chew et al. (2004) and Yin et al. (2007)}

1. How often are medical forms and pamphlets written in a way that is difficult for you to read and understand?
Always
Often
Sometimes
Occasionally
Never

2. How often are medication labels written in a way that is difficult for you to read and understand?
Always
Often
Sometimes
Occasionally
Never

3. How often are medical forms difficult for you to understand and fill out?
Always
Often
Sometimes
Occasionally
Never

4. How often are written recommendations for therapy/treatment difficult for you to understand?
Always
Often
Sometimes
Occasionally
Never

5. How often are verbal recommendations for therapy/treatment difficult for you to understand?
Always
Often
Sometimes
Occasionally
Never

6. How often do you have problems getting to your clinic appointments at the right time because of difficulty understanding written instructions about when and why you must come to the clinic?
Always
Often
Sometimes
Occasionally
Never

7. How often do you have problems learning about your (or your child's) medical condition because of difficulty understanding written or verbal information?
Always
Often
Sometimes
Occasionally
Never

8. How often do you need someone (like a family member, friend, hospital/clinic worker or caregiver) to help you read and understand hospital materials?
Always
Often
Sometimes
Occasionally
Never

\section{Appendix B. Preliminary framework for speech-language pathologists when making practical decisions to assist} client health literacy and recall

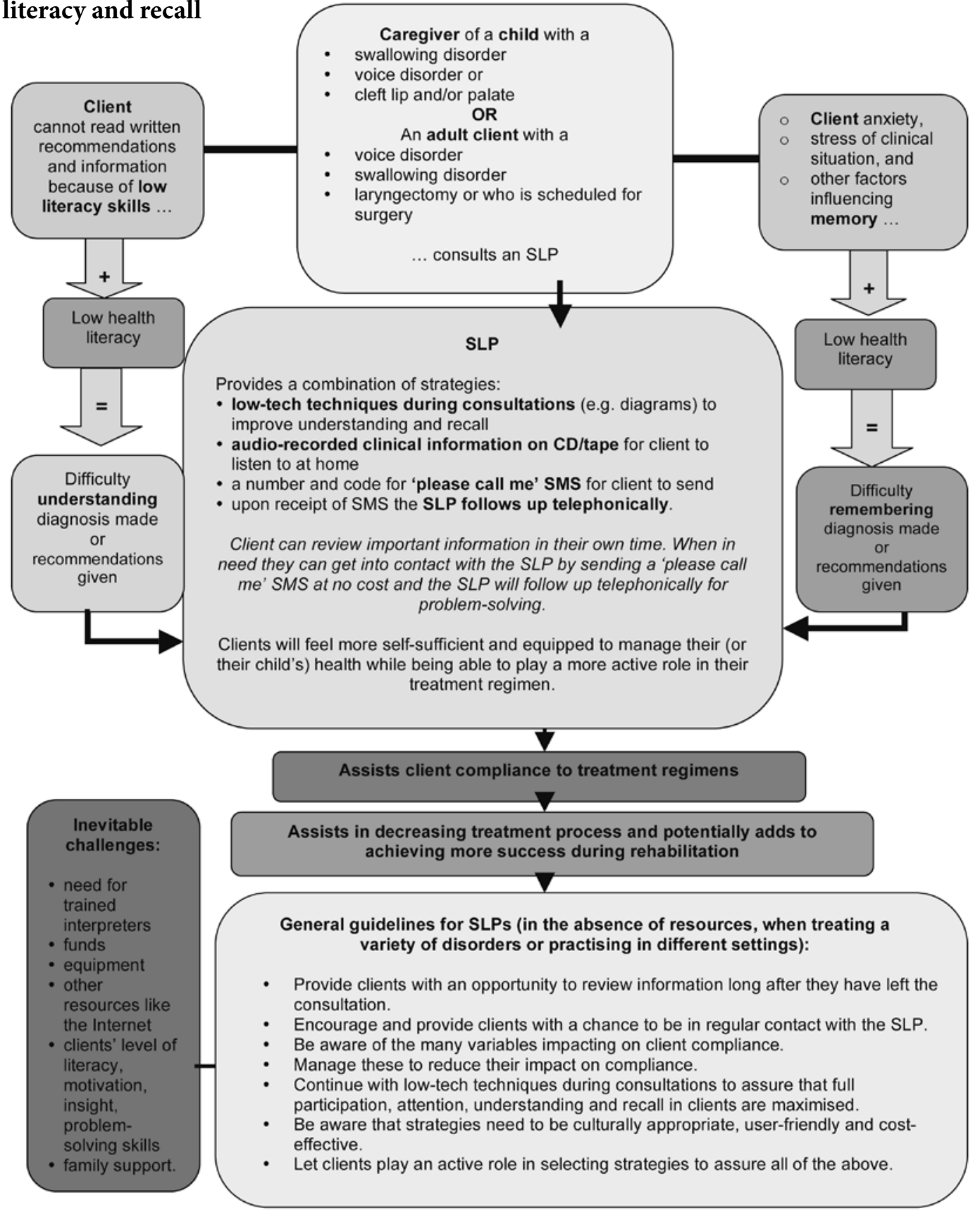

